\title{
Honeycomb-Like Mosaic at the Border of Layers 1 and 2 in the Cerebral Cortex
}

\author{
Noritaka Ichinohe, ${ }^{1}$ Fumino Fujiyama, ${ }^{2}$ Takeshi Kaneko, ${ }^{2}$ and Kathleen S. Rockland ${ }^{1}$ \\ ${ }^{1}$ Laboratory for Cortical Organization and Systematics, RIKEN, Brain Science Institute, Wako, Saitama 351-0198, Japan, and ${ }^{2}$ Department of Morphological \\ Brain Science, Graduate School of Medicine, Kyoto University, Kyoto 606-8501, Japan
}

In this report, we present evidence of a small-scale modularity $(<100 \mu \mathrm{m})$ at the border of layers 1 and 2 in neocortical areas. The modularity is best seen in tangential sections, with double-labeling immunohistochemistry to reveal overlapping or complementary relationships of different markers. The pattern is overall like a reticulum or mosaic but is described as a "honeycomb," in which the walls and hollows are composed of distinct afferent and dendritic systems. We demonstrate the main components of the honeycomb in rat visual cortex. These are as follows: (1) zinc-enriched, corticocortical terminations in the walls, and in the hollows, thalamocortical terminations (labeled by antibody against vesicular glutamate transporter 2 and by cytochrome oxidase); (2) parvalbumin-dense neuropil in the walls that partly colocalizes with elevated levels of glutamate receptors $2 / 3$, NMDAR receptor 1 , and calbindin; and (3) dendritic subpopulations preferentially situated within the walls (dendrites of layer 2 neurons) or hollows (dendrites of deeper neurons in layers 3 and 5). Because the micromodularity is restricted to layers 2 and $1 \mathrm{~b}$, without extending into layer 3 , this may be another indication of a laminar-specific substructure at different spatial scales within cortical columns. The suggestion is that corticocortical and thalamocortical terminations constitute parallel circuits at the level of layer 2, where they are segregated in association with distinct dendritic systems. Results from parvalbumin staining show that the honeycomb mosaic is not limited to rat visual cortex but can be recognized at the layer $1-2$ border in other areas and species.

Key words: columnar organization; zinc-enriched corticocortical terminals; thalamocortical terminals; parvalbumin; dendritic minicolumn; rat visual cortex; cytochrome oxidase

\section{Introduction}

Vertical modularity is one of the defining characteristics of cortical structures, but the specific features are not identical across areas. In primary sensory areas, a conspicuous modularity has been associated with thalamocortical (TC) terminations, especially in layer 4 (Lund, 1988; Chmielowska et al., 1989; DeFelipe and Jones, 1991; Casagrande and Kaas, 1994; Rockland, 1998), but in limbic areas, where layer 4 is absent or poorly developed, it is the superficial layers that have a pronounced modularity (Amaral et al., 1987; Kostovic et al., 1993).

In a previous study of rat granular retrosplenial cortex (Ichinohe and Rockland, 2002a), we demonstrated a new system of dendritic bundling in layer 1. This originates from GABAergic inhibitory neurons and comingles with apical dendrites of layer 2 pyramidal neurons (Wyss et al., 1990). As a further demonstration of the complex organization of the superficial layers in this area, we noted that the dendritic bundles merge, at the border of layers 1 and 2, into a honeycomb-like structure, with walls consisting of parvalbumin (PV)-dense neuropil.

In this report, we present evidence for a similar small-scale modularity at the border of layers 1 and 2 in neocortical areas.

\footnotetext{
Received Aug. 21, 2002; revised Nov. 20, 2002; accepted Nov. 22, 2002.

This work was supported by the Brain Science Institute, RIKEN. We thank Kyoko Shirasawa, Miyoko Bellinger, Yoshiko Abe, and Peter M. Kaskan for their excellent technical assistance, Adrian Knight for photographic assistance, and Michiko Fujisawa for manuscript preparation.

Correspondence should be addressed to Dr. Noritaka Ichinohe, Laboratory for Cortical Organization and Systematics, RIKEN, Brain Science Institute, 2-1 Hirosawa, Wako-shi, Saitama 351-0198, Japan. E-mail: nichinohe@brain.riken.go.jp.

Copyright $\odot 2003$ Society for Neuroscience $\quad 0270-6474 / 03 / 231372-11 \$ 15.00 / 0$
}

The pattern is overall like a reticulum or mosaic but is described as a honeycomb in which the walls and hollows are revealed by markers for distinct neurochemical substances, afferents, or dendritic subpopulations. Three aspects of the honeycomb provide a new perspective on cortical organization. First, its localization to layers 2 and $1 \mathrm{~b}$ suggests the particular importance of this stratum, even outside limbic areas. Second, because the micromodularity is restricted to layers 2 and $1 b$, this is additional evidence for a laminar-specific substructure, at different spatial scales, within the cortical column as traditionally understood in relation to thalamic terminations in layer 4 (for review, see Mountcastle, 1997). Third, the particular composition, as we will show in Results, involves high levels of zinc and NMDA receptor 1 (NMDAR1), substances that have been specifically involved in plasticity effects.

As a first step, we have performed a detailed characterization of the honeycomb in rat visual cortex, using cell type-specific and functionally related markers. PV immunohistochemistry was also used to investigate the occurrence of the honeycomb in other areas and species.

Some of these results have been published previously in abstract form (Ichinohe and Rockland, 2002b).

\section{Materials and Methods}

Experimental subjects. Forty-five adult male Wistar rats ( $>9$ weeks old) were used in this study. Blocks from cat $(n=3)$ and monkey tissues $(n=$ 3 ) were excised from brains used in other studies. All experimental protocols were approved by the Experimental Animal Committee of the RIKEN Institute and were performed in accordance with the Guidelines 
for the Use of Animals in Neuroscience Research (The Society for Neuroscience).

Fixation and tissue preparation. Adult rats were anesthetized with Nembutal (100 mg/kg). They were perfused transcardially, in sequence, with $0.9 \%$ saline and $0.5 \%$ sodium nitrite, and $4 \%$ paraformaldehyde with or without saturated $15 \%$ picric acid, in $0.1 \mathrm{M}$ phosphate buffer (PB), $\mathrm{pH}$ 7.3. Four rats designated for zinc histochemistry were perfused with $0.1 \mathrm{M} \mathrm{PB}$ containing $0.1 \%$ sodium sulfide and then $0.1 \%$ sodium sulfide and $4 \%$ paraformaldehyde. Postfixation in the same fixative was for $2 \mathrm{hr}$. Then the brains were placed in 30\% sucrose and after sinking were cut into $40-\mu \mathrm{m}$-thick tangential or coronal sections on a freezing microtome.

Immunoperoxidase staining for $P V$. Sections were incubated for $1 \mathrm{hr}$ with $0.1 \mathrm{M}$ PBS, pH 7.3, containing $0.5 \%$ Triton X-100 and 5\% normal goat serum (PBS-TG) at room temperature and then for $40-48 \mathrm{hr}$ at $4^{\circ} \mathrm{C}$ with PBS-TG containing mouse monoclonal anti-PV antibody (Swant, Bellinzona, Switzerland; 1:50,000). After they were rinsed, the sections were placed in PBS-TG containing biotinylated goat anti-mouse IgG (Vector, Burlingame, CA; 1:200) for $1.5 \mathrm{hr}$ at room temperature. Immunoreactivity was visualized by $\mathrm{ABC}$ incubation (one drop of reagents per $7 \mathrm{ml} 0.1 \mathrm{M} \mathrm{PB}$; ABC Elite kits, Vector, Burlingame, CA) followed by diaminobenzidine histochemistry with $0.03 \%$ nickel ammonium sulfate.

Double immunofluorescence. After $1 \mathrm{hr}$ of immunoblocking with PBS-TG at room temperature, free-floating sections were incubated for $40-48 \mathrm{hr}$ at $4^{\circ} \mathrm{C}$ in a mixture of two different antibodies. The antibody for PV was chosen from two antibodies from mouse or rabbit to avoid using the same animal host as for the second antibody, namely, anti-PV monoclonal mouse antibody (Swant; 1:5000), or anti-PV polyclonal rabbit antibody (Swant; 1:1000). The second antibody was chosen from the following: anti-calbindin K-28 (CB) monoclonal mouse antibody (Swant; 1:1,000), anti-calretinin (CR) polyclonal rabbit antibody (Swant; 1:800), anti-glutamate decarboxylase $65 \mathrm{kDa}$ (GAD65) mouse monoclonal antibody (GAD-6 supernatant obtained from the Developmental Studies Hybridoma Bank, Department of Biological Sciences, University of Iowa, Iowa City, IA; 1:1) (Chang and Gottlieb, 1988), anti-GABA receptor type $\mathrm{A} \alpha 1$ subunit (GABAa $\alpha 1$ ) polyclonal rabbit antibody (Chemicon, Temecula, CA; 1:5000), anti-glutamate receptor 2 and 3 (GluR2/3) polyclonal rabbit antibody (Chemicon; 1:100), anti-microtubule-associated protein 2 (MAP2) monoclonal mouse antibody (Chemicon; 1:2000), anti-myelin basic protein (MBP) monoclonal mouse antibody (Chemicon; 1:100), antiNMDAR1 polyclonal rabbit antibody (Chemicon; 1:20), anti-somatostatin (SOM) polyclonal rat antibody (Chemicon; 1:400), anti-vesicular glutamate transporter 2 (VGluT2) affinitypurified guinea-pig antibody (Fujiyama et al., 2001; Kaneko and Fujiyama, 2002; Kaneko et al., $2002 ; 665 \mu \mathrm{g} / \mathrm{ml}$ ). Finally, the sections were incubated for $1.5 \mathrm{hr}$ in PBS-TG containing the suitable combination of secondary antibodies. These were chosen from the following: Alexa Fluo 488conjugated anti-mouse IgG polyclonal goat antibody (Molecular Probes, Eugene, OR; 1:200), Alexa Fluo 488-conjugated anti-guinea-pig IgG polyclonal goat antibody (Molecular Probes; 1:200), Alexa Fluo 488-conjugated anti-rat IgG polyclonal goat antibody (Molecular Probes; 1:200), and Alexa Fluo 594-conjugated antirabbit IgG polyclonal goat antibody (Molecular Probes; 1:200). Fluorescent photomicrographs were obtained with a Zeiss LSM 5 Pascal confocal microscope (Jena, Germany), and images labeled with different fluorochromes were merged with software of this confocal system.

For controls, one of the primary antibodies was omitted. No immunofluorescence was detected for the antibody under these circumstances.

Double labeling combining immunohistofluorescence for $P V$ and zinc, cytochrome oxidase, acetylcholinesterase, or NADPH-diaphorase histochemistry. Reactions for the following histochemistry were performed according to previously detailed protocols: zinc (Akagi et al., 2001), cytochrome oxidase (CO) (WongRiley, 1979), acetylcholinesterase (AchE) (Tsuji, 1998), and NADPH-diaphorase (NADPH-d) (Scherer-Singler et al., 1983). Subsequently, we continued with immunofluorescence for PV. 
Measurements and analysis. Quantitative analysis was achieved with the aid of a Neurolucida System (MicroBrightField, Colchester, VT). Tangential sections were selected that had been reacted for PV or CO. The centers of the PV-immunoreactive (PV-ir) honeycomb hollows and CO-positive patches were plotted in an area of at least $120,000 \mu \mathrm{m}^{2}$ from two tissue sections for each structure, using a $20 \times$ objective lens. The nearest center-to-center distance was obtained by using NeuroExplorer analysis software (MicroBrightField). Although many of our figures are shown at lower magnification, we examined all materials using higher magnification $(200$ or $400 \times)$ in an attempt to evaluate nonspecific staining. We note that our observations relate to strong PV-ir labeling. There is some possibility that SOM and PV may colocalize, but this pertains to PV-ir profiles that are weak and has been shown to be very slight in neocortex (Kosaka et al., 1987; Kubota et al., 1994; Gonchar and Burkhalter, 1997).

Identification of areas. Visual cortex in the rat has been divided into subfields according to several criteria and nomenclatures (Montero, 1981; Malach, 1989; Zilles, 1990; Paxinos and Watson, 1998; Rumberger et al., 2001). In this report, we concentrate on area V1, both monocular and binocular subdivisions, and use the terminology of Paxinos and Watson (1998).

No obvious difference between subdivisions of V1 was noticed as regards the honeycomb, and we describe results from both regions. In coronal sections, posterior to the dentate gyrus, we identified area V1 at lateral 2.0-4.0. In tangential sections, we used reference coordinates in relation to the posterior pole to identify V1: anterior 1.0 and lateral 2.0-4.0; anterior 3.0 and lateral 2.0-5.0. Other areas are also identified according to Paxinos and Watson (1998).

In addition to guidance from the published literature, we verified histologically that we were within area V1. Both AchE and MBP showed clear changes in layers 4 and 5 at the lateral and medial borders of area V1 (Zilles et al., 1984).

Identification of layers 1 and 2 (rat visual cortex). As frequently described, layer 1 is a conspicuously cell-sparse zone $(\sim 150 \mu \mathrm{m}$ wide $)$ in Nissl stains. In myelin preparations, however, a thin, myelin-dense outer zone, layer 1a $(\sim 70 \mu \mathrm{m}$ wide), can be distinguished from a myelin-sparse inner zone, layer $1 \mathrm{~b}(\sim 80 \mu \mathrm{m}$ wide $)$. A thin, outermost part of layer la again appears myelin sparse, but this is not considered separately in this report. In Nissl stains, layers 2 and 3 are frequently not distinguished. However, on the basis of our results, we have delineated layer 2 as a distinct zone, $\sim 100-120 \mu \mathrm{m}$ in thickness, subjacent to layer 1 .

\section{Results}

The honeycomb structure can be demonstrated by several markers with overlapping or complementary relationships. Because PV [which stains a subpopulation of GABAergic cortical interneurons (Kosaka et al., 1987; Kubota et al., 1994; Gonchar and Burkhalter, 1997)] reliably and strongly shows the honeycomb pattern,
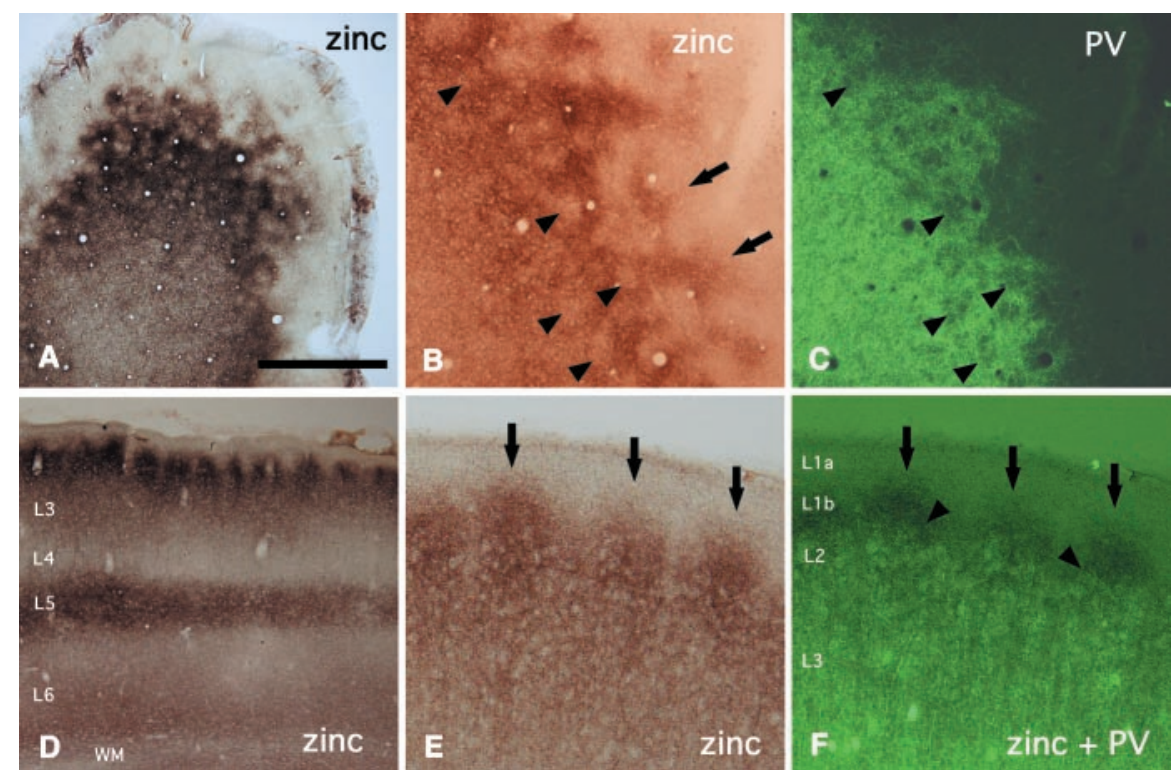

Figure 2. Zinc-enriched terminals are located in the walls. A, Tangential section. Zinc walls surround open hollows. $B, C$, Tangential section. Double labeling for zinc and PV indicates that the zinc pattern closely colocalizes with the PV walls in layer 2; however, the zinc walls extend into layer $1 \mathrm{~b}$ (arrows). Arrowheads point to corresponding hollows in both markers. D, Zinc staining, in coronal section, shows a conspicuous modularity at the border of layers 1 and 2 . Lateral is to the left. E, $F$, Double labeling for zinc and PV confirms that zinc walls (arrows) extend into layer 1b, higher than PV walls (arrowheads). WM, White matter. Scale bar (shown in $A$ ): $A, D, 500 \mu \mathrm{m} ; B, C, E, F, 100 \mu \mathrm{m}$.

and because the reaction protocol is easily compatible with other markers, PV is used as the standard reference for double labeling throughout this study. In the first part of Results, therefore, we report the basic structure of the honeycomb as demonstrated by PV. In the subsequent sections, we consider several afferent and other neuronal components, which may be part of a specialized circuitry. Some of these, especially as shown by zinc and VGluT2,
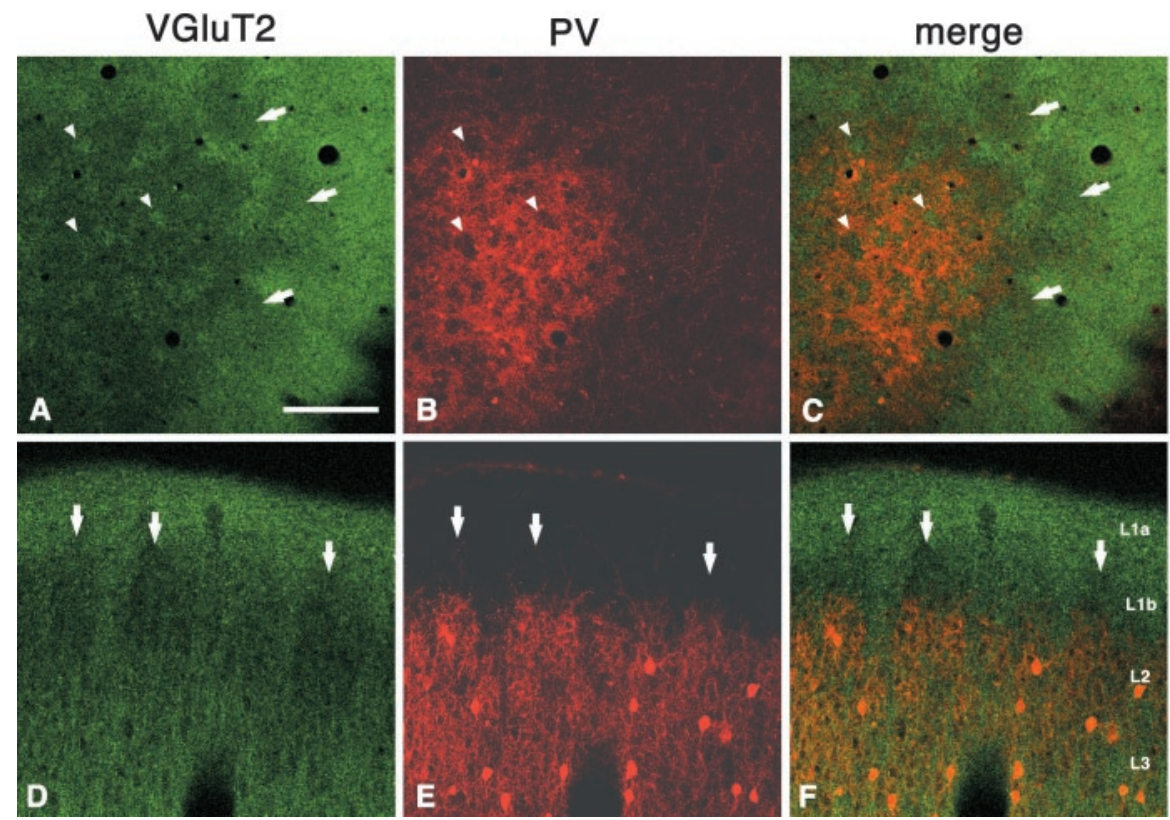

Figure 3. Immunohistochemistry for VGluT2 shows dense uniform staining in layer 1a but a discontinuous periodic pattern in layers $1 \mathrm{~b}$ and 2 ( $A-C$, tangential section; $D-F$, coronal section). Double labeling for VGluT2 and PV shows that VGluT2-ir dense regions in layer 2 are situated within the PV hollows. Arrowheads point to corresponding spaces (hollows for PV and dense regions for VGluT2). The complementary relationship extends into layer 1b, where VGluT2 sparse areas (arrows) can be seen above PV walls, in D-F. Scale bar (shown in A): A-C, $200 \mu \mathrm{m} ; D-F, 100 \mu \mathrm{m}$. 

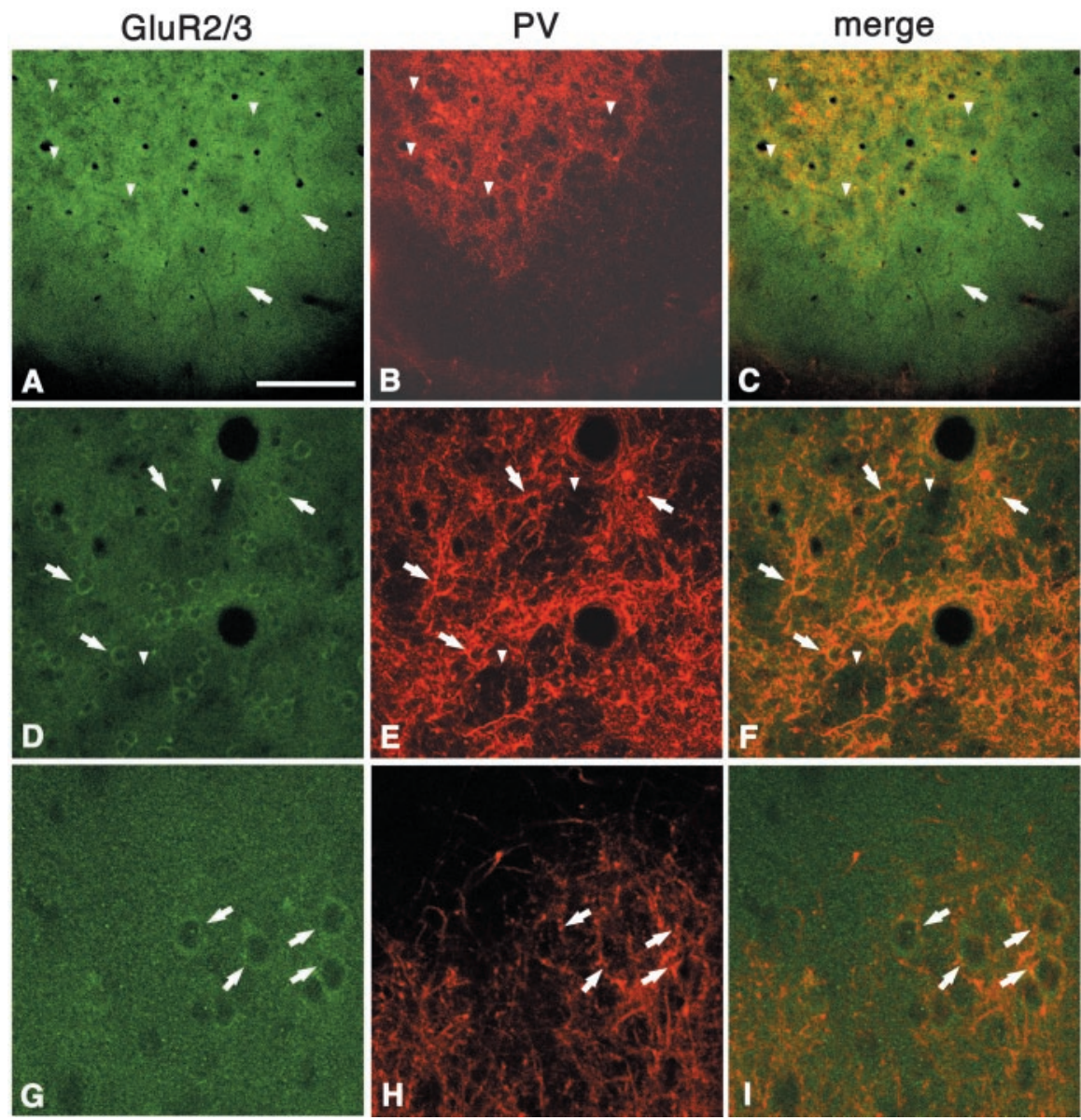

Figure 4. Double labeling for GluR2/3 and PV shows colocalization of these two markers in the walls in layer 2 ( $A-C$, tangential section; $D-F$, higher magnification; $G-I$, higher magnification in coronal section). As with zinc, the GluR2/3-labeled neuropil extends higher, into layer $1 \mathrm{~b}(A, C$, arrows). GluR2/3-ir somata are localized in the walls ( $D-F, G-I$, arrows) and surrounded by PV-ir basket-like puncta (D-I, arrows). Arrowheads point to corresponding hollows in both markers. Scale bar (shown in $A$ ): $A-C, 200$ $\mu \mathrm{m} ; D-F, 100 \mu \mathrm{m} ; G-I, 30 \mu \mathrm{m}$.

extend into layer $1 \mathrm{~b}$. At the end of Results, we discuss other markers, some of which seem not to conform to either the walls or hollows, and present preliminary evidence that the honeycomb occurs in other regions and other species.

\section{Honeycomb shown by PV}

Tangential sections stained for PV clearly reveal a honeycomblike organization, with distinct walls and hollows in the superficial layers of rat V1 (Fig. 1A-E). The walls of the honeycomb consist of PV-ir small, fine, terminal-like particles and PV-ir cell bodies, fibers, and dendritic elements (Fig. $1 D, J$ ). In serial tangential sections, each honeycomb compartment is recognizable in one to three sections; that is, through $\sim 120 \mu \mathrm{m}$ (section thickness $=40 \mu \mathrm{m}$ ). Below this, the honeycomb merges into a homogeneously dense PV-ir neuropil (Fig. $1 A-C$ ). We define layer 2 as the layer with $\mathrm{PV}$-ir honeycomb pattern, and comparison with Nissl stains (for cell bodies) confirms a slightly increased cell density at this level, relative to layer 3 (Fig. $1 \mathrm{H}, \mathrm{I}$ ). The center-tocenter spacing of the hollows is $\sim 80 \mu \mathrm{m}$ (mean value) and ranges from 50 to $120 \mu \mathrm{m}$. Although the honeycomb pattern is discerned most easily in tangential sections, it can also be recognized in radial sections, where the hollows appear as a series of notches (Fig. 1G). Double staining for PV and Nissl substance shows that the PV hollows tend to contain fewer cells than do the walls (Fig. $1 E, F, H, I$ ).

The identity of the terminal-like particles was investigated by staining for GAD65, which is localized in GABAergic terminals (Erlander et al., 1991). Doubleimmunofluorescent staining for PV and GAD65 demonstrates colocalization of these two markers (Fig. $1 J-L$ ), as would be expected if the small PV-ir particles were GABAergic terminals. More particularly, double-labeled structures frequently made basket-like terminations on immunonegative somata (Fig. 1L), consistent with classical depictions of PV basket endings.

\section{Excitatory terminal markers}

Next we investigated how other terminations, especially excitatory terminations, are related to the PV honeycomb. For this purpose, we used zinc and VGluT2 as general markers for two distinct connectional systems. Zinc is known to distinguish a subpopulation of corticocortical (CC) excitatory terminals (Slomianka et al., 1990; Garret et al., 1992; Casanovas-Aguilar et al., 1998, 2002). VGluT2, in contrast, is a marker for TC terminals (Fujiyama et al., 2001; Kaneko and Fujiyama, 2002; Kaneko et al., 2002). Histochemistry for zinc in tangential sections shows fine zincpositive small particles in a distinct honeycomb pattern (Fig. $2 \mathrm{~A}$ ). As established by double labeling, the zinc pattern closely colocalizes with the PV-ir walls in layer 2 (Fig. 2B,C). The zinc walls, however, are taller and extend into layer $1 \mathrm{~b}$ (Fig. $2 B-$ $F)$. In coronal section, zinc-negative honeycomb hollows appear as gaps, or notches, of reduced labeling, and the greater height of the walls, extending into layer $1 \mathrm{~b}$, can be discerned easily (Fig. $2 D, E$ ). In layer $1 \mathrm{a}$, zinc staining is very weak, and below layer 2 , it also becomes gradually weaker.

Immunohistochemistry for VGluT2 shows uniformly dense staining in layer la but a discontinuous, periodic pattern in layers $1 \mathrm{~b}$ and 2. With double labeling for VGluT2 and PV, the VGluT2-ir dense regions in layer 2 can be seen to lie within the PV hollows (Fig. 3). One can infer, therefore, that VGluT2-ir TC terminals are complementary to zinc-enriched CC terminals in layers 1 and 2. Both periodic systems extend into layer $1 \mathrm{~b}$, higher than the PV honeycomb walls (Fig. 3D-F). Below layer 2, immmunoreactivity for VGluT2 becomes stronger through the deeper part of layer 3, where narrow vertical bundles, possibly corresponding to ascending axons, are frequently in evidence.

\section{Cell body and neuropil markers}

The complementary relationship between zinc and VGluT2 strongly supports the possibility that the honeycomb is a distinct specialization in the upper layers. To further characterize this structure, we screened additional markers suitable for visualizing putative neuronal subpopulations or postsynaptic structures. These are GluR2/3, a marker of excitatory pyramidal neuronal 
cell bodies and dendritic shafts and spines (Petralia and Wenthold, 1992; GutierrezIbarluzea, 1997); NMDAR1, expressed by $80 \%$ of cortical neurons (Conti et al., 1994), including many with the morphological features of pyramidal neurons (Aoki et al., 1994); CB, a marker, in rat cortex, for GABAergic and some pyramidal neurons (Celio, 1990; Gonchar and Burkhalter, 1997); MAP2, a marker for thick apical dendrites (Escobar et al., 1986); GABAa $\alpha 1$, the most prevalent GABAa subunit, contained in $80 \%$ of GABAa receptors (Benke et al., 1991); and GluR5/6/7, kainate receptor, which stains many pyramidal neurons in their dendrites and cell bodies (Vickers et al., 1993).

GluR2/3 immunoreactivity reveals a distinct honeycomb pattern in layers $1 b$ and 2 (Fig. 4A). Double labeling for PV shows that the regions dense for GluR2/3 colocalize with the PV dense walls, although as with zinc, these extend higher into layer $1 \mathrm{~b}$ (Fig. 4A-C). As expected from Nissl staining, GluR2/3immunopositive cell bodies in layer 2 (presumably excitatory pyramidal neurons) are concentrated in the walls (Fig. $4 D-F)$. The GluR2/3 label extends into layer $1 \mathrm{~b}$, where it is probably composed of apical dendritic components of layer 2 pyramidal neurons. Most GluR2/3 cell bodies are surrounded by PV-ir basket-like puncta (Fig. 4D-I), consistent with other reports of PV-ir terminals surrounding pyramidal cell bodies. Below layer 2, GluR2/3 immunoreactivity is about as dense as in the honeycomb wall but is overall diffuse, with no indication of periodicity.

Immunoreactivity for NMDAR1 shows a periodic pattern that, after double-labeling reactions, is seen to correspond well with the PV honeycomb (Fig. 5A-C). The walls are composed of NMDAR1-ir cell bodies, along with proximal dendrites and fine particles (Fig. 5D-I). In coronal sections, many of the NMDAR1-ir cells have the appearance of pyramidal neurons (Fig. 5G), and none are double labeled for PV. NMDAR1-ir cell bodies, like GluR2/3-ir cells, are frequently surrounded by PV-ir basket-like terminations (Fig. 5D-I), and their proximal dendrites also seem to be targeted by PV-ir puncta (Fig. $5 F, I$ ). In our material, no particular NMDAR1-ir pattern is discernable in layer 1; however, Johnson et al. (1996, their Fig. 1b), using an antibody against NMDAR1-C1-splice variant, illustrate distinct protrusions into layer $1 \mathrm{~b}$, similar to our results with zinc. Below layer 2, the number of NMDAR1-ir cell bodies is sparser than in layer 2.

$\mathrm{CB}$ immunoreactivity demonstrates a honeycomb pattern closely similar to that of PV (Fig. 6A-F) but extending into layer 1 b. The CB walls in layer 2 consist of many weakly positive neurons (probably pyramidal neurons) (Kubota et al., 1994), with a few strongly positive neurons (presumably GABAergic) (Fig. $6 D-F)$. Some CB-ir neurons are double labeled for PV. Both the weakly and strongly CB-ir neurons are associated with PV-ir puncta (Fig. 6G-I). In layer 1a, CB staining is very weak, and below layer 2, CB staining becomes gradually weaker (Fig. 6D), similar to zinc staining.

In summary, GluR2/3, NMDAR1, and CB, all of which stain cell bodies and proximal dendrites, have a periodic pattern that is systematically related to the PV-ir honeycomb (but extends higher into layer $1 \mathrm{~b}$ than does the PV-ir staining).

\section{Dendritic markers}

Other prominent components of the superficial layers are pyramidal cell apical dendrites. In fact, a distinct organization of apical dendrites has been reported previously by several laboratories using MAP2 antibody (Escobar et al., 1986; Peters and Sethares, 1991a; Peters and Yilmaz, 1993). These studies report that MAP2-ir apical dendritic shafts of pyramidal neurons in layers 3 and 5 form distinct bundles, which are about the same dimension $(<100 \mu \mathrm{m})$ as the layer 2 honeycomb. By analysis of coronal and tangential sections, we confirmed that MAP2-ir dendrites form distinct bundles, but we would further suggest that there are several subpopulations.

First, double labeling for MAP2 and PV indicates bundles of strongly MAP2-ir apical dendrites that are contained primarily in honeycomb hollows (Fig. 7A-I). In serial sections, the thick dendritic bundles in the hollows can be followed down to layer 5 . 

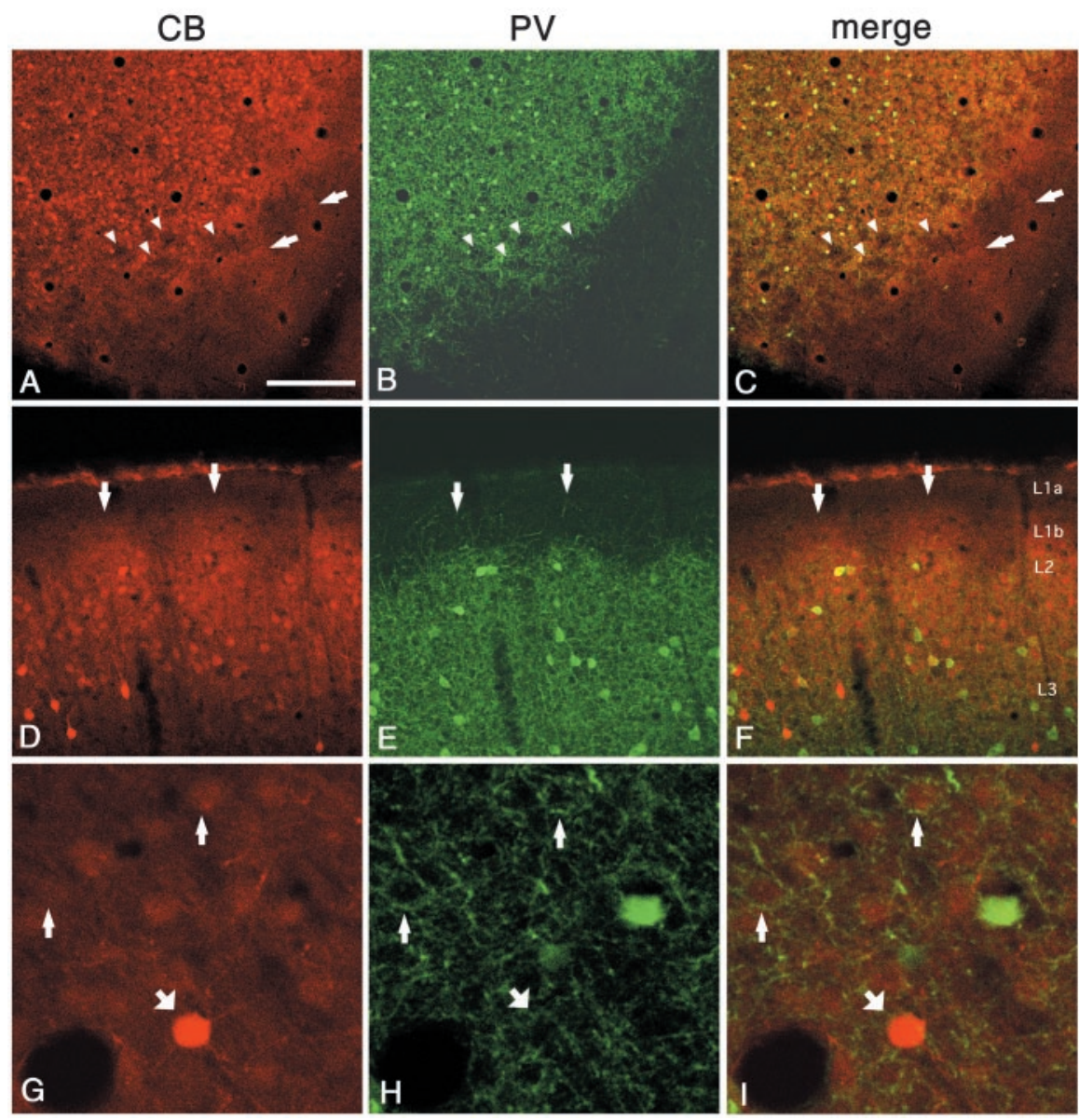

Figure 6. Double labeling for $C B$ and PV demonstrates that regions dense for $C B$ colocalize with PV in the walls $(A-C$, tangential section; $D-F$, coronal section). As with zinc, the CB pattern extends higher, into layer $1 \mathrm{~b}$ (arrows). Arrowheads point to corresponding hollows in both markers. G-I, Higher magnification from walls (tangential section). Thin and thick arrows point, respectively, to weakly and strongly CB-ir cell bodies surrounded by basket-like PV-ir terminal puncta. Scale bar (shown in A):A-C, $200 \mu \mathrm{m} ; D-F, 100 \mu \mathrm{m} ; G-I, 30 \mu \mathrm{m}$.

From layer 5, two dendritic bundles frequently merged together to form a single bundle within one honeycomb hollow. Apical dendrites from layer 3 could be seen joining with these deeper bundles, as reported previously (Escobar et al., 1986; Peters and Sethares, 1991a; Peters and Yilmaz, 1993). Smaller bundles of thick apical dendrites are less strictly confined within the hollows. A second subpopulation consists of apical dendrites of neurons in the honeycomb walls (in layer 2). These are thinner dendrites, closer to the pia surface, and less frequently labeled by MAP2. Their origin from superficial neurons, which are not stained by MAP2, can be inferred by double labeling for MAP2 and PV, because the position of cell bodies is rendered visible by PV-ir basket-like terminations (Fig. 7D-F). With MAP2 staining for dendrites, therefore, the separation between walls and hollows is not as clear as with PV and other markers.

In layer 1b, MAP2-ir dendrites in the hollows bifurcate, becoming thinner, and the distal apical tufts frequently arch over the honeycomb walls (Fig. $7 D-F$ ). In contrast with VGluT2, MAP2 immunohistochemistry does not show any distinct pattern in layer $1 b$.

GABAa $\alpha 1$ is a general neuropil marker but often yields an image of vertically oriented, presumably dendritic processes. In our material, immunoreactivity for GABAa $\alpha 1$ shows a distinct periodicity that, especially in tangential sections, has a honeycomb configuration. After double labeling with PV, regions high in GABAa $\alpha 1$, similar to VGluT2, can be seen to coincide with PV hollows (Fig. $8 A-F)$. Bundles of GABAa $\alpha 1$-ir dendritelike structures in layer 2 extend into layer $1 \mathrm{~b}$ before merging into a uniform neuropil (Fig. 8D). Interestingly, in development, the strong expression of GABAa $\alpha 1$ is well matched with thalamically innervated layers (layers 1, 3, and 4) in V1 and S1 (Paysan et al., 1994) and is dependent on thalamic innervation (Paysan et al., 1997).

GluR5/6/7 immunohistochemistry stains thick apical dendrites strongly and cell somata weakly (data not shown). The overall staining pattern in layer 2 is similar to MAP2 immunoreactivity. That is, immunoreactivity is higher in the PV hollows, without any distinct pattern in layer 1. Faintly immunopositive neurons are found in honeycomb walls, and some neurons are also double labeled for PV and GluR5/6/7.

\section{Other neuronal markers}

Because PV demarcates subpopulations of GABAergic neurons, it seemed important to screen for markers of other GABAergic subpopulations (i.e., SOM and CR) (Kosaka et al., 1987; Kubota et al., 1994; Gonchar and Burkhalter, 1997). Reacting for SOM does not result in any obvious pattern in layers 1 or 2 (data not shown). This is not surprising because SOM-ir neurons are not common at this level, but neither did CR exhibit any particular pattern in relationship to $\mathrm{PV}$ walls or hollows (Fig. 9A-E). CR-ir cell bodies are only weakly targeted by PV-ir terminations, judging from the apparent absence of basket-like specializations (Fig. $9 F$ )

We also examined classical histochemical markers, such as $\mathrm{CO}, \mathrm{AChE}$, NADPH-d, and myelin staining (by immunohistochemistry for MBP). Staining for AChE, NADPH-d, and MBP does not show any honeycomb pattern in layers 1 and 2. CO staining, however, shows a faintly patchy pattern in layers $1 \mathrm{~b}$ and 2 , in tangential sections (Fig. 10A,B). Double histochemistry for $\mathrm{CO}$ and $\mathrm{PV}$ shows that $\mathrm{CO}$ activity is preferentially elevated in the PV honeycomb hollows, although continuing into layer $1 \mathrm{~b}$ (Fig. $10 B, C)$. The CO patches are about the same size as PV-ir honeycomb hollows (center-to-center distance, mean $80 \mu \mathrm{m}$; range, 50-124 $\mu \mathrm{m}$; measurements are from layer 2 where the patches are most conspicuous.). In layer $1 \mathrm{a}$, the $\mathrm{CO}$ patches merge into denser diffuse staining, as in VGluT2-ir (Fig. 10A,B). In other thalamic recipient layers in V1 (i.e., layers 4 and $6 a$ and the lower part of layer 3), CO activity is differentially higher but does not exhibit any periodicity.

\section{Other area and other species}

To test whether the honeycomb specialization is peculiar to rat visual cortex, we screened several additional areas for PV. Sections reacted for PV show a honeycomb mosaic in area V2, adjacent to area V1. Tangential sections through barrel cortex and medial prefrontal area show a distinct honeycomb configuration in layer 2 (Fig. $11 A, B$ ). In 
barrel cortex, the honeycomb is confined to layer 2, without continuing into layer 3 , and is of a smaller scale than the underlying barrels in layer 4 ( $\sim 80$ vs $\sim 300 \mu \mathrm{m}$ center-tocenter distance). The honeycomb structure can be recognized in other species, as seen by PV staining: cat area 17 and several areas in monkey (Fig. 11C,D). There are slight differences in size and distinctness, and additional work is necessary to clarify areaspecific patterns of overlapping and complementary relationships of different substances, as shown for rat visual cortex.

\section{Discussion}

Our results demonstrate a reticulated or honeycomb-like organization at the border of layers 1 and 2. The term "honeycomb" may be deceptive, because the organization is not strictly regular; however, it conveys the small-scale dimension and the complementary, wall-and-hollow pattern as seen with single labels. The main components of the honeycomb in rat visual cortex are as follows: (1) segregated afferent systems that can be attributed to CC (zinc) and TC (VGluT2) terminations; (2) PV-dense walls that colocalize with elevated levels of GluR2/3, NMDAR1, and CB; and (3) dendritic systems at least partially segregated to the walls (dendrites of layer 2 neurons) and hollows (dendrites of deeper neurons in layers 3 and 5) (Fig. 12). The implication is that CC and TC circuitries are to some extent two parallel systems at the level of layer 2 . The CC terminations may differentially target the dendrites of layer 2 pyramids, and TC terminations may target the distal apical dendrites of deeper neurons in layers 3 and 5. Some elements, however, such as CR-ir neurons, do not strictly fit the honeycomb pattern but perhaps have a separate organization in layer 2 . Because the honeycomblike pattern is also observed, in a different degree of distinctness, in other areas and other species, this small-scale structure in layer 2 may be a basic feature of neocortical organization.

\section{Comparison with other work}

Although it is surprising that such a conspicuous structure has not been reported

Figure 8. Immunohistochemistry for $\mathrm{GABAa} \alpha 1$ shows dense uniform staining in layer 1a but a discontinuous periodic pattern in layers $1 \mathrm{~b}$ and $2(A-C$, tangential section; $D-F$, coronal section). Double labeling for GABAa $\alpha 1$ and PV shows that GABAa $\alpha 1$-dense regions in layer 2 are situated within the PV hollows, like VGluT2. Arrowheads point to corresponding hollows for PV and dense regions for GABAa $\alpha 1$. The complementary relationship extends into layer $1 \mathrm{~b}$, where GABAa $\alpha 1$ sparse areas (arrows) lie above PV walls, in D-F. Scale bar (shown in A): A-C, $200 \mu \mathrm{m} ; D-F, 100 \mu \mathrm{m}$.
MAP2
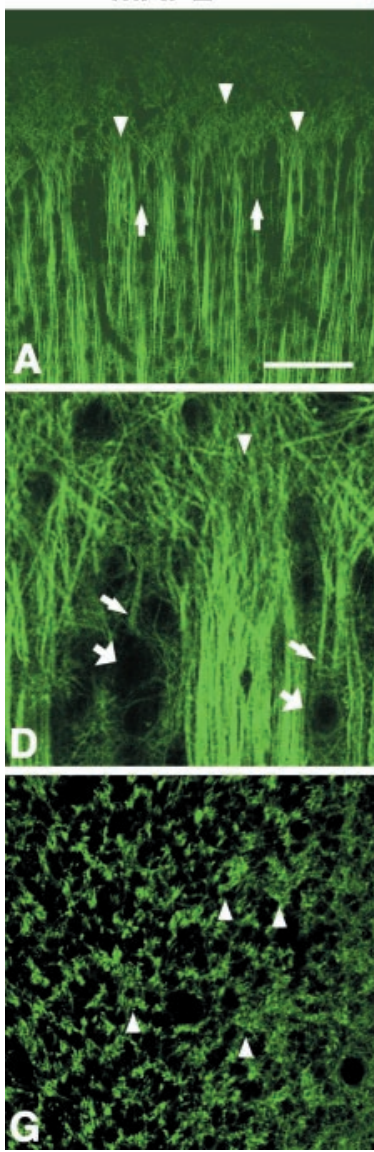

PV

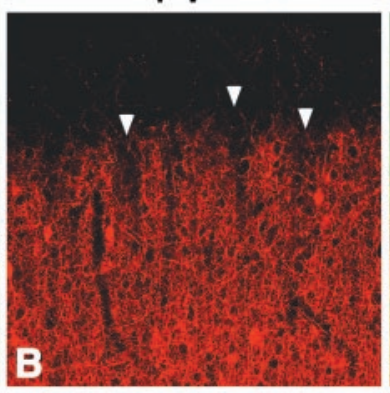

merge

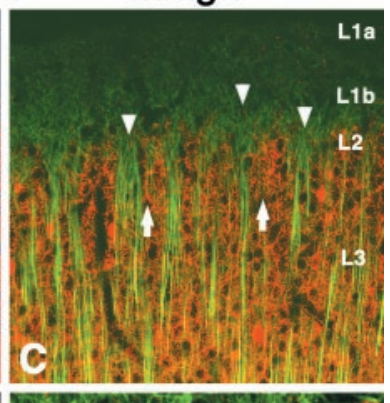

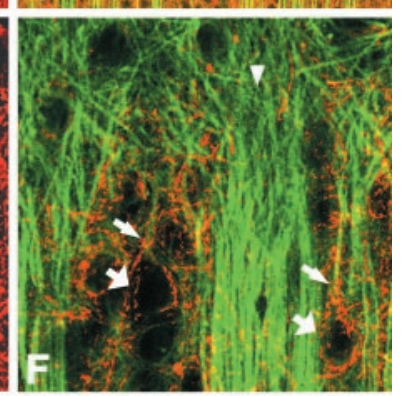
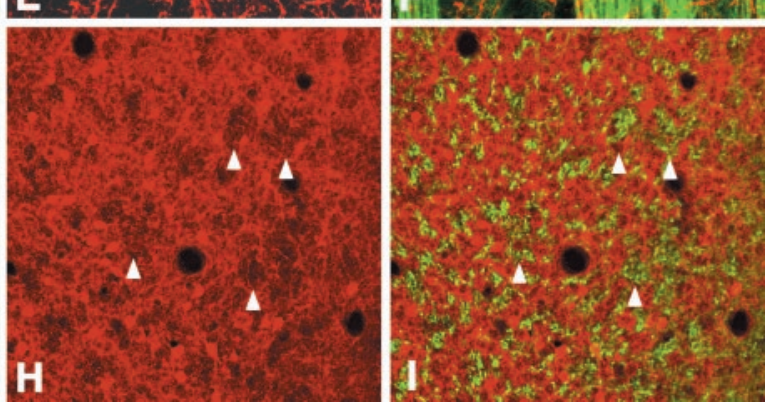

Figure 7. Double labeling for MAP2 and PV shows that large bundles of apical dendrites (probably from neurons from layer 3 and layer 5) lie predominantly within PV hollows ( $A-C$, coronal section; $D-F$, higher magnification; $G-I$, tangential section). The separation between walls and hollows is less clear than in PV, and some MAP2-ir dendrites, weakly stained and forming small bundles, can be seen in the honeycomb walls ( $A$, C, arrows). In contrast with VGluT2, MAP2 immunohistochemistry does not show any distinct pattern in layer $1 \mathrm{~b}$, which is uniformly filled with fine MAP2-ir particles, probably representing apical dendritic tufts. Apical dendrites from layer 2 pyramidal neurons ( $D-F$, thinner arrows) are less frequently found to be MAP2-ir. These can be traced, however, to weakly MAP2-ir somata or unstained somata, visualized by PV-ir basket-like terminals ( $D-F$, thicker arrows). Arrowheads point to corresponding PV hollows and MAP2-ir large dendritic bundles. Scale bar (shown in A):A-C, $100 \mu \mathrm{m} ; D-F, 25 \mu \mathrm{m}$; $\mathrm{G}-\mathrm{l}, 100 \mu \mathrm{m}$.

GABAa alpha1
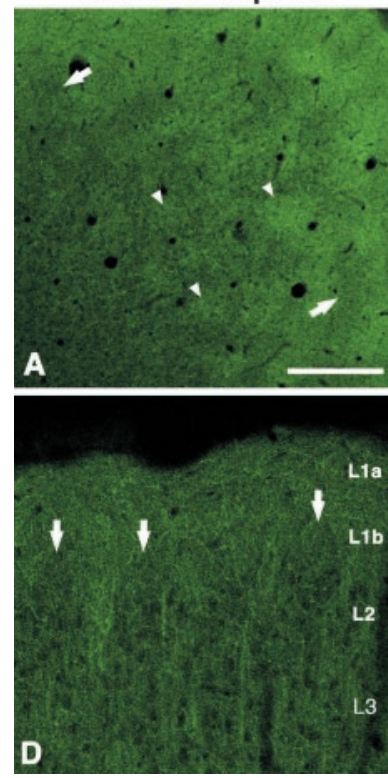

PV
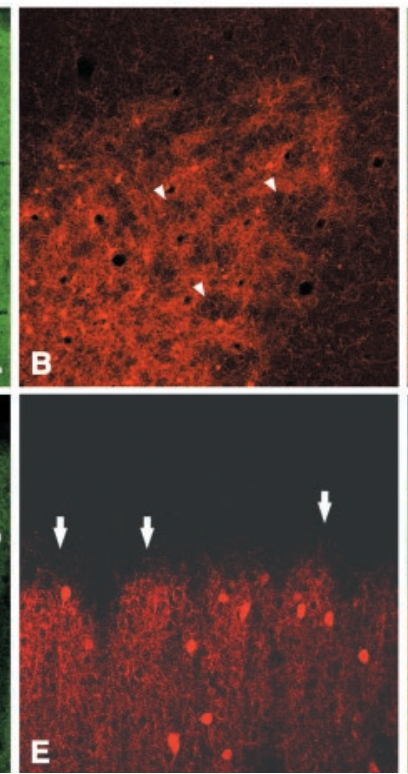

merge
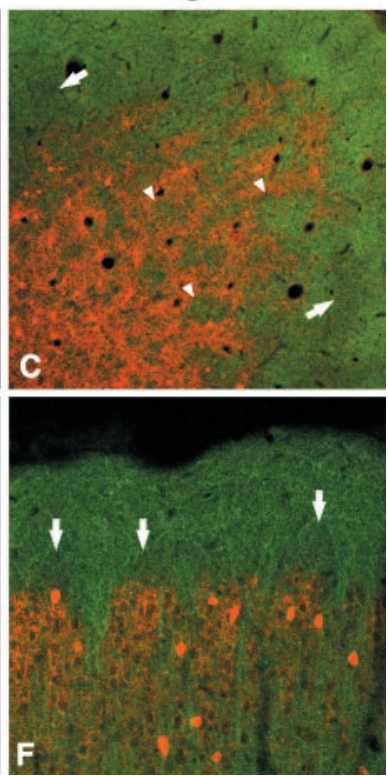

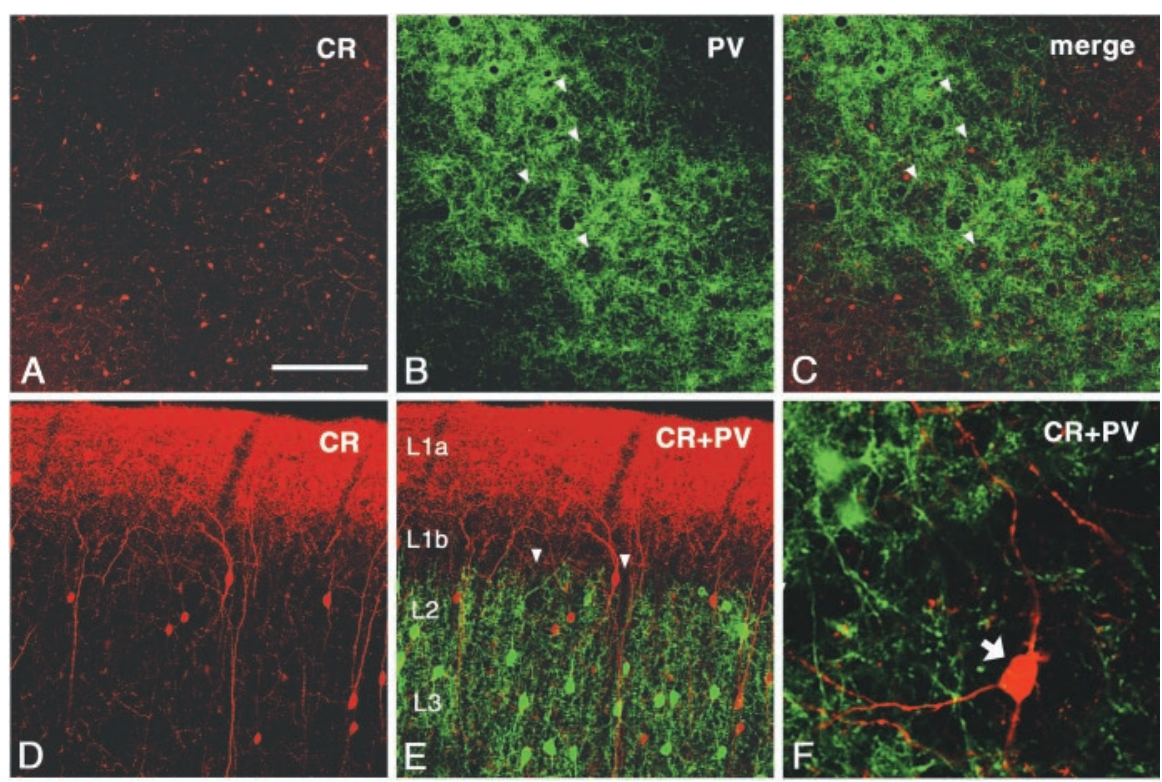

Figure 9. CR staining shows cell bodies distributed in layers 1 and 2 and a dense band of neuropil staining in layer $1 \mathrm{a}(A-C$ tangential section; $D, E$, coronal section). In layers $1 \mathrm{~b}$ and 2, CR-ir cell bodies show no clear relationship to PV walls or hollows (arrowheads).F, Higher magnification of coronal section. (R-ir cell bodies (arrow) are not obviously targeted by PV-ir terminations, judging from the apparent absence of basket-like specializations. Scale bar (shown in $A$ ): $A-C, 200 \mu \mathrm{m} ; D, E, 100 \mu \mathrm{m}$; in $F, 30 \mu \mathrm{m}$.

(within hollows, where several bundles may merge together), but we emphasize that these are only one of several dendritic systems. Notably, another population is made up of smaller caliber dendrites of layer 2 pyramidal neurons. These seem to remain spatially segregated within honeycomb walls, where they overlap with zincenriched, putative CC inputs and with concentrations of PV-positive neuropil (Fig. 12).

The segregation of different dendritic systems is accentuated specifically at the level of the honeycomb in layers $1 \mathrm{~b}$ and 2 . In upper layer 1 , there is considerable intermingling of the dendritic neuropil, and in layer 3, thick dendritic bundles continue, but not within the honeycomb organization. Yet other distinct subpopulations may be distinguishable; for example, dendrites of layer 6 neurons were identified as being separate by earlier investigations (Escobar et al., 1986; Peters and Kara, 1987).

One implication of these results is that in neocortex, as in limbic cortices, layer 2 has a distinct and prominent role. Our re-

co
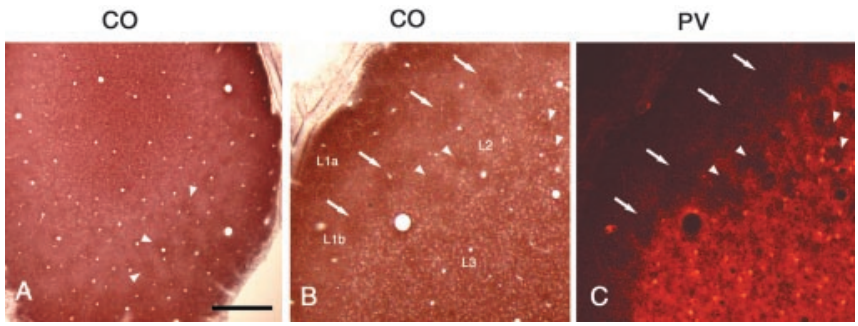

Figure 10. CO histochemistry shows diffuse strong staining in layer 1 and a patchy pattern in layers $1 \mathrm{~b}$ and 2 ( $A$, tangential section; $B$, deeper, semi-tangential section). Double staining for $C O(B)$ and $P V(C)$ shows that $C 0$-dense regions in layer 2 are situated within the PV hollows, like VGluT2. Arrowheads point to $C 0$-dense patches in $A$ and to corresponding hollows for $\mathrm{PV}$ and dense regions for $\mathrm{C} O$ in $B$. C, Arrows point to $C 0$-positive region in layer $1 \mathrm{~b}$, above the $\mathrm{PV}$-ir hollows. Scale bar (shown in $A$ ): $A, 500 \mu \mathrm{m} ; B, C, 100 \mu \mathrm{m}$.

previously, the honeycomb pattern can easily be missed. This is because of its thinness and the fact that it is best seen in serial tangential sections, with double-labeling to reveal overlapping or complementary patterns. In retrospect, however, a periodic modularity in layer 2 can be discerned in many published images [e.g., Nissl staining (Peters and Kara, 1985, their Fig. 18); PV and CB (Celio, 1990, their Fig. 9G,H); zinc (Perez-Clausell, 1996, his Fig. 15); MAP2 (Schmolke and Kunzle, 1997, their Fig. 2b); NMDAR1 C1 splice variants (Johnson et al., 1996, their Fig. 9B)].

Among the honeycomb components, one of them, the apical dendritic bundles, has in fact been described by other investigators. These studies reported that pyramidal neurons in layers 3 and 5 form compact bundles of apical dendrites [mouse (Escobar et al., 1986); rat (Peters and Kara, 1987); rabbit (Schmolke and Viebahn, 1986); cat (Peters and Yilmaz, 1993); monkey (Peters and Sethares, 1991a)] and further discussed whether these might be substrates of cortical minicolumns (Peters, 1994; Mountcastle, 1997). Our results demonstrate similar apical dendritic bundles cent study of the periallocortical granular retrosplenial region in rats identified a honeycomb organization in layer 2 , which is continuous with laterally adjacent areas (Ichinohe and Rockland, 2002a). More work is necessary, however, to determine regional and species differentiation.

A second implication is that there is a significant laminarspecific substructure across the cortical thickness. Anatomically, it is well established that cortical columns, when considered as 300 - to $500-\mu \mathrm{m}$-wide structures (equivalent to TC domains in layer 4), are not homogeneous. For example, in primate visual cortex, TC terminations in layers 3 (the CO patches), $4 \mathrm{~A}, 4 \mathrm{C} \alpha$, $4 \mathrm{C} \beta$, and 6 are all at different spatial scales (Lund, 1988; Casagrande and Kaas, 1994). Physiological studies also report laminar-specific differences in magnification factors (Blasdel and Fitzpatrick, 1984; Tootell et al., 1988a). In the case of the layer 2 honeycomb, it is not clear whether this is best regarded as a closely integrated subdivision of a pia-to-white matter "column" or, perhaps more likely, whether it might be operating in parallel with a TC unit, based in layer 4 . One might even suppose that layer 4 is primarily concerned with topographic, local operations, whereas layer 2 might operate as a widespread network [see also Jones (1998) on topographically specific and diffuse TC inputs to layers 4 and 1, respectively].

In scale, the layer 2 honeycomb is very similar to the layer $4 \mathrm{~A}$ honeycomb in primate area $\mathrm{V} 1$, but in the latter, thalamic afferents coincide with PV-ir and CB-ir neuropil in the walls (Peters and Sethares, 1991b). The hollows are reported to contain pyramidal cell clusters displaced from layer 4B (Peters and Sethares, 1991b; Hendry and Bhandari, 1992; Preuss and Coleman, 2002).

The alternation of TC and CC afferents in the layer 1-2 honeycomb conforms to a common feature of cortical modularity that is believed, in general, to subserve parallel processing. A close comparison is with the rat barrel field, where the cell-dense barrels receive thalamic afferents from the ventral posterior medial nucleus and have short-range intrinsic connections, whereas the 
inter-barrel septa receive afferents from the posterior medial thalamus, have long-range intrinsic connections, and have more extensive extrinsic connections (Kim and Ebner, 1999). The CO patches in cat and primate are another natural comparison. These are known to match with direct thalamic inputs, and with high GABAa $\alpha 1$ immunoreactivity, but to be complementary with zinc, like the layer 2 honeycomb (Hendry et al., 1990; Dyck and Cynader, 1993; Murphy et al., 1995). Unlike the honeycomb, however, no dendritic bundling or stratification has been associated with these deeper CO blobs.

How does the organized arrangement of TC and CC inputs in layer 2 relate to dendritic targets? Although more work is necessary here also, the implication is of a high degree of connectional selectivity. In layer 2, TC terminations target the distal apical tufts of deeper pyramidal neurons, whereas CC inputs preferentially colocalize with apical dendrites of superficial pyramidal neurons and with PV-ir neuropil. In layer 1a, however, both dendritic populations in their distalmost portions are accessible to TC but not to zinc-enriched CC terminations. Stratification along the distal dendrites recalls the piriform cortex, where distal apical tufts of pyramidal neurons in layers 2 and 3 receive stratified inputs. These are from extrinsic olfactory afferents, in layer 1a, and from zinc-enriched cortical association inputs, in layer $1 \mathrm{~b}$ (Haberly, 1998). Similarly, in vitro results have indicated that local connections of interneurons and pyramidal neurons are not probablistic or random but rather highly selective (for review, see Silberberg et al., 2002).

\section{Functional significance}

Is the honeycomb in rat visual cortex expressly related to visual processing? It may be relevant in this regard that laminar differences have been reported in response to spatial frequency. In particular, layer 2 neurons in the rat have a higher spatial frequency preference than do neurons in the deeper layers (Girman et al., 1999). According to our results, layer 2 neurons are likely to be situated in the CO-weak honeycomb walls. This would agree with results, in both monkeys and cats, in which neurons in the CO blobs (our "hollows") preferentially respond to low spatial frequencies, and those located in interblobs (our "walls") respond to high spatial frequencies (Tootell et al., 1988b; Born and Tootell, 1991; Shoham et al., 1997).

One might speculate that the honeycomb may be related to developmental phenomena. That is, in early neonate, optical recordings of brain slices labeled with fluorescent calcium indicator reveal distinct domains of spontaneously coactive neurons, coupled by gap junctions (Yuste et al., 1992, 1995; Peinado et al., 1993). The domain size $(50-120 \mu \mathrm{m})$ is very similar to the honeycomb spacing. Paysan et al. (1994) demonstrated aggregates $(80-120 \mu \mathrm{m})$ in layer 3 of GABAa $\alpha 1$-ir pyramidal neurons and dendrites, again of dimensions similar to the GABAa $\alpha 1$-ir dendritic bundles in the adult honeycomb

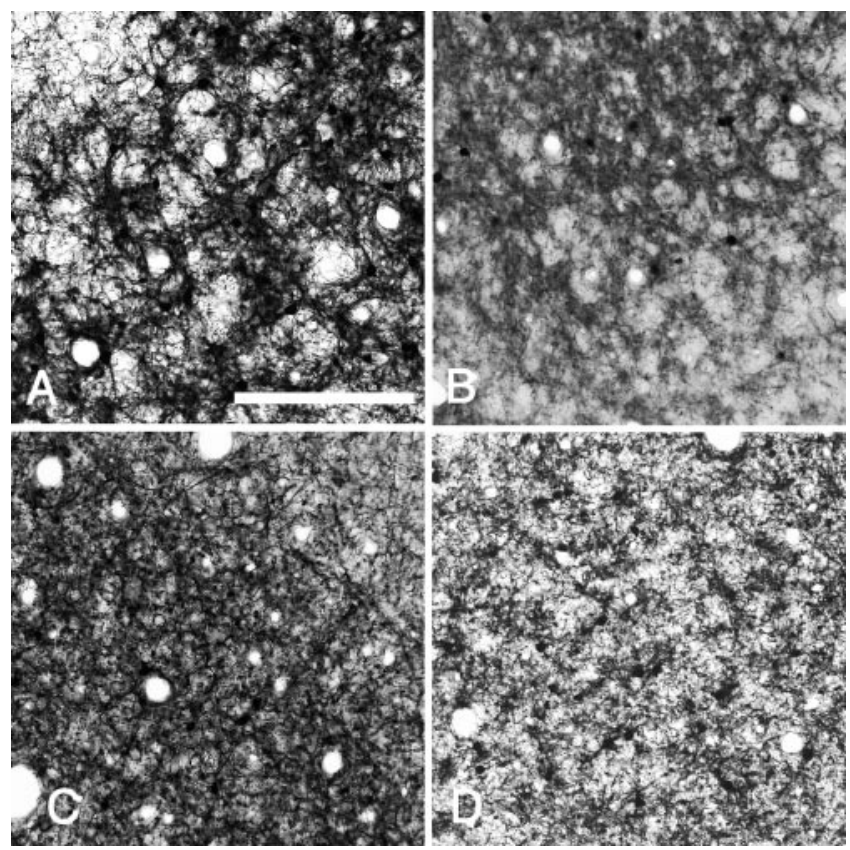

Figure 11. A honeycomb-like mosaic can be seen in layer 2 in other areas and other species. Tangential sections reacted for PV by immunoperoxidase method. $A$, Rat barrel cortex. $B$, Rat medial prefrontal cortex. C, Cat visual cortex, D, Monkey primary auditory cortex. Scale bar, $200 \mu \mathrm{m}$.

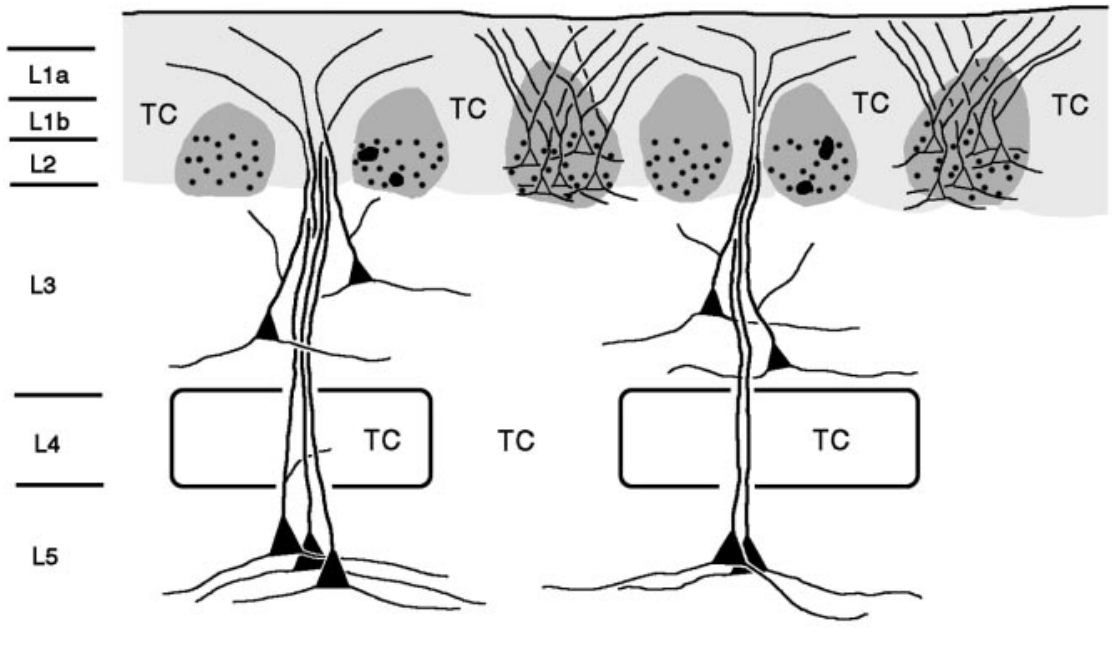

Preferential Location

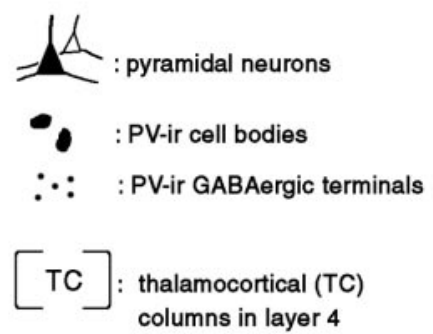

Figure 12. Highly schematic summary of the micromodularity of layers 1 and 2 of the rat visual cortex. Honeycomb walls in layer 2 (darker shading) are preferentially occupied by somata and proximal dendrites of layer 2 pyramids. These comingle with PV-ir GABAergic terminals and zinc-enriched corticocortical terminals. The zinc-enriched terminals extend into layer $1 \mathrm{~b}$, where they are likely to target the dendrites from layer 2 pyramidal neurons. Apical dendrites of deeper pyramidal neurons preferentially occupy honeycomb hollows (lighter shading) and colocalize with VGluT2-ir thalamocortical terminals. Other markers related to the honeycomb mosaic are listed. The degree of segregation and precise microcircuitry organization will need to be investigated further. 
hollows observed in the present study. Finally, it is interesting to note the higher levels of zinc and NMDAR1 within the honeycomb, substances that have been consistently associated with plasticity (Bear, 1996; Li et al., 2001; Brown and Dyck, 2002).

\section{References}

Akagi T, Kaneda M, Ishii K, Hashikawa T (2001) Differential subcellular localization of zinc in the rat retina. J Histochem Cytochem 49:87-96.

Amaral DG, Insausti R, Cowan WM (1987) The entorhinal cortex of the monkey: I. Cytoarchitectonic organization. J Comp Neurol 264:326-355.

Aoki C, Venkatesan C, Go CG, Mong JA, Dawson TM (1994) Cellular and subcellular localization of NMDA-R1 subunit immunoreactivity in the visual cortex of adult and neonatal rats. J Neurosci 14:5202-5222.

Bear MF (1996) Progress in understanding NMDA-receptor-dependent synaptic plasticity in the visual cortex. J Physiol (Paris) 90:223-227.

Benke D, Mertens S, Mohler H (1991) Ubiquitous presence of GABAa receptors containing the alphal-subunit in rat brain demonstrated by immunoprecipitation and immunohistochemistry. Mol Neuropharmacol 1:103-110.

Blasdel GG, Fitzpatrick D (1984) Physiological organization of layer 4 in macaque striate cortex. J Neurosci 4:880-895.

Born RT, Tootell RB (1991) Spatial frequency tuning of single units in macaque supragranular striate cortex. Proc Natl Acad Sci USA 88:7066-7070.

Brown CE, Dyck RH (2002) Rapid, experience-dependent changes in levels of synaptic zinc in primary somatosensory cortex of the adult mouse. J Neurosci 22:2617-2625.

Casagrande VA, Kaas JH (1994) The afferent, intrinsic, and efferent connections of primary visual cortex in primates. In: Cerebral cortex, Vol 10 (Peters A, Rockland KS, eds), pp 201-259. New York: Plenum.

Casanovas-Aguilar C, Roblet C. Perez-Clausell J, Bueno-Lopez JL (1998) Zinc-rich afferents to the rat neocortex: projections to the visual cortex traced with intracerebral selenite injections. J Chem Neuroanat 15:97-109.

Casanovas-Aguilar C, Miro-Bernie N, Perez-Clausell J (2002) Zinc-rich neurones in the rat visual cortex give rise to two laminar segregated systems of connections. Neuroscience 110:445-458.

Celio MR (1990) Calbindin D-28k and parvalbumin in the rat nervous system. Neuroscience 35:375-475.

Chang YC, Gottlieb DI (1988) Characterization of the proteins purified with monoclonal antibodies to glutamic acid decarboxylase. J Neurosci 8:2123-2130.

Chmielowska J, Carvell GE, Simons DJ (1989) Spatial organization of thalamocortical and corticothalamic projection systems in the rat SmI barrel cortex. J Comp Neurol 285:325-338.

Conti F, Minelli A, Molnar M, Brecha NC (1994) Cellular localization and laminar distribution of NMDAR1 mRNA in the rat cerebral cortex. J Comp Neurol 343:554-565.

DeFelipe J, Jones EG (1991) Parvalbumin immunoreactivity reveals layer IV of monkey cerebral cortex as a mosaic of microzones of thalamic afferent terminations. Brain Res 562:39-47.

Dyck RH, Cynader MS (1993) An interdigitated columnar mosaic of cytochrome oxidase, zinc, and neurotransmitter-related molecules in cat and monkey visual cortex. Proc Natl Acad Sci USA 90:9066-9069.

Erlander MG, Tillakaratne NJ, Feldblum S, Patel N, Tobin AJ (1991) Nucleotide, OMIM, protein two genes encode distinct glutamate decarboxylases. Neuron 7:91-100.

Escobar MI, Pimienta H, Caviness Jr VS, Jacobson M, Crandall JE, Kosik KS (1986) Architecture of apical dendrites in the murine neocortex: dual apical dendritic systems. Neuroscience 17:975-989.

Fujiyama F, Furuta T, Kaneko T (2001) Immunocytochemical localization of candidates for vesicular glutamate transporters in the rat cerebral cortex. J Comp Neurol 435:379-387.

Garret B, Sorensen JC, Slomianka L (1992) Fluoro-gold tracing of zinccontaining afferent connections in the mouse visual cortices. Anat Embryol (Berl) 185:451-459.

Girman SV, Sauve Y, Lund RD (1999) Receptive field properties of single neurons in rat primary visual cortex. J Neurophysiol 82:301-311.

Gonchar Y, Burkhalter A (1997) Three distinct families of GABAergic neurons in rat visual cortex. Cereb Cortex 7:347-358.

Gutierrez-Ibarluzea I (1997) GABAergic neurons with AMPA GluR1 and
GluR2/3 immunoreactivity in the rat striate cortex. NeuroReport 8:2495-2499.

Haberly LB (1998) Olfactory cortex. In: The synaptic organization of the brain (Shepherd GM, ed), pp 377-416. New York: Oxford UP.

Hendry SH, Bhandari MA (1992) Neuronal organization and plasticity in adult monkey visual cortex: immunoreactivity for microtubuleassociated protein 2. Vis Neurosci 9:445-459.

Hendry SH, Fuchs J, deBlas AL, Jones EG (1990) Distribution and plasticity of immunocytochemically localized GABAA receptors in adult monkey visual cortex. J Neurosci 10:2438-2450.

Ichinohe N, Rockland KS (2002a) Parvalbumin positive dendrites colocalize with apical dendritic bundles in rat retrosplenial cortex. NeuroReport 13:757-761.

Ichinohe N, Rockland KS (2002b) Honeycomb-like structure at the border of layers 1 and 2 in the cerebral cortex. Jpn Neurosci Abstr 25:259.

Johnson RR, Jiang X, Burkhalter A (1996) Regional and laminar differences in synaptic localization of NMDA receptor subunit NR1 splice variants in rat visual cortex and hippocampus. J Comp Neurol 368:335-355.

Jones EG (1998) Viewpoint: the core and matrix of thalamic organization. Neuroscience 85:331-345.

Kaneko T, Fujiyama F (2002) Complementary distribution of vesicular glutamate transporters in the central nervous system. Neurosci Res 42:243-250.

Kaneko T, Fujiyama F, Hioki H (2002) Immunohistochemical localization of candidates for vesicular glutamate transporters in the rat brain. J Comp Neurol 444:39-62.

Kim U, Ebner FF (1999) Barrels and septa: separate circuits in rat barrels field cortex. J Comp Neurol 408:489-505.

Kosaka T, Heizmann CW, Tateishi K, Hamaoka Y, Hama K (1987) An aspect of the organizational principle of the gamma-aminobutyric acidergic system in the cerebral cortex. Brain Res 409:403-408.

Kostovic I, Petanjek Z, Judas M (1993) Early areal differentiation of the human cerebral cortex: entorhinal area. Hippocampus 3:447-458.

Kubota Y, Hattori R, Yui Y (1994) Three distinct subpopulations of GABAergic neurons in rat frontal agranular cortex. Brain Res 649:159-173.

Li Y, Hough CJ, Frederickson CJ, Sarvey JM (2001) Induction of mossy fiber $\rightarrow$ CA3 long-term potentiation requires translocation of synaptically released $\mathrm{Zn}^{2+}$. J Neurosci 21:8015-8025.

Lund J (1988) Anatomical organization of macaque monkey striate visual cortex. Annu Rev Neurosci 11:253-288.

Malach R (1989) Patterns of connections in rat visual cortex. J Neurosci 9:3741-3752.

Montero VM (1981) Comparative studies on the visual cortex. In: Cortical sensory organization, Vol 2, Multiple visual area (Woolsey CN, ed), pp 33-81. Clifton, NJ: Humana.

Mountcastle VB (1997) The columnar organization of the neocortex. Brain 120:701-722.

Murphy KM, Jones DG, Van Sluyters RC (1995) Cytochrome-oxidase blobs in cat primary visual cortex. J Neurosci 15:4196-4208.

Paxinos G, Watson C (1998) The rat brain in stereotaxic coordinates. San Diego: Academic.

Paysan J, Bolz J, Mohler H, Fritschy JM (1994) GABAA receptor alpha 1 subunit, an early marker for area specification in developing rat cerebral cortex. J Comp Neurol 350:133-149.

Paysan J, Kossel A, Bolz J, Fritschy JM (1997) Area-specific regulation of gamma-aminobutyric acid type A receptor subtypes by thalamic afferents in developing rat neocortex. Proc Natl Acad Sci USA 94:6995-7000.

Peinado A, Yuste R, Katz LC (1993) Gap junctional communication and the development of local circuits in neocortex. Cereb Cortex 3:488-498.

Perez-Clausell J (1996) Distribution of terminal fields stained for zinc in the neocortex of the rat. J Chem Neuroanat 11:99-111.

Peters A (1994) The organization of the primary visual cortex in the macaque. In: Cerebral cortex, Vol 10 (Peters A, Rockland KS, eds), pp 201259. New York: Plenum.

Peters A, Kara DA (1985) The neuronal composition of area 17 of rat visual cortex. I. The pyramidal cells. J Comp Neurol 234:218-241.

Peters A, Kara DA (1987) The neuronal composition of area 17 of rat visual cortex. IV. The organization of pyramidal cells. J Comp Neurol 260:573-590.

Peters A, Sethares C (1991a) Organization of pyramidal neurons in area 17 of monkey visual cortex. J Comp Neurol 306:1-23. 
Peters A, Sethares C (1991b) Layer IVA of rhesus monkey primary visual cortex. Cereb Cortex 1:445-462.

Peters A, Yilmaz E (1993) Neuronal organization in area 17 of cat visual cortex. Cereb Cortex 3:49-68.

Petralia RS, Wenthold RJ (1992) Light and electron immunocytochemical localization of AMPA-selective glutamate receptors in the rat brain. J Comp Neurol 318:329-354.

Preuss TM, Coleman GQ (2002) Human-specific organization of primary visual cortex: alternating compartments of dense Cat-301 and calbindin immunoreactivity in layer 4A. Cereb Cortex 12:671-691.

Rockland KS (1998) Complex microstructures of sensory cortical connections. Curr Opin Neurobiol 8:545-551.

Rumberger A, Tyler CJ, Lund JS (2001) Intra- and inter-areal connections between the primary visual cortex V1 and the area immediately surrounding V1 in the rat. Neuroscience 102:35-52.

Scherer-Singler U, Vincent SR, Kimura H, McGeer EG (1983) Demonstration of a unique population of neurons with NADPH-diaphorase histochemistry. J Neurosci Methods 9:229-234.

Schmolke C, Kunzle H (1997) On the presence of dendrite bundles in the cerebral cortex of the Madagascan lesser hedgehog tenrec and the redeared pond turtle. Anat Embryol (Berl) 196:195-213.

Schmolke C, Viebahn C (1986) Dendrite bundles in lamina II/III of the rabbit neocortex. Anat Embryol (Berl) 173:343-348.

Shoham D, Hubener M, Schulze S, Grinvald A, Bonhoeffer T (1997) Spatiotemporal frequency domains and their relation to cytochrome oxidase staining in cat visual cortex. Nature 385:529-533.

Slomianka L, Danscer G, Frederickson CJ (1990) Labeling of the neurons of origin of zinc-containing pathways by intraperitoneal injections of sodium selenite. Neuroscience 38:843-854.

Silberberg G, Gupta A, Markram H (2002) Stereotypy in neocortical microcircuits. Trends Neurosci 25:227-230.
Tootell RB, Switkes E, Silverman MS, Hamilton SL (1988a) Functional anatomy of macaque striate cortex. II. Retinotopic organization. J Neurosci 8:1531-1568.

Tootell RB, Silverman MS, Hamilton SL, Switkes E, De Valois RL (1988b) Functional anatomy of macaque striate cortex. V. Spatial frequency. J Neurosci 8:1610-1624.

Tsuji S (1998) Electron microscopic localization of acetylcholinesterase activity in the central nervous system: chemical basis of a catalytic activity of Hatchett's brown (cupric ferrocyanide) precipitate revealed by 3,3' diaminobenzidine. Folia Histochem Cytobiol 36:67-70.

Vickers JC, Huntley GW, Edwards AM, Moran T, Rogers SW, Heinemann SF, Morrison JH (1993) Quantitative localization of AMPA/kainate and kainate glutamate receptor subunit immunoreactivity in neurochemically identified subpopulations of neurons in the prefrontal cortex of the macaque monkey. J Neurosci 13:2982-2992.

Wong-Riley M (1979) Changes in the visual system of monocularly sutured or enucleated cats demonstrable with cytochrome oxidase histochemistry. Brain Res 171:11-28.

Wyss JM, van Groen T, Sripanidkulchai K (1990) Dendritic bundling in layer I of granular retrosplenial cortex: intracellular labeling and selectivity of innervation. J Comp Neurol 295:33-42.

Yuste R, Peinado A, Katz LC (1992) Neuronal domains in developing neocortex. Science 257:665-669.

Yuste R, Nelson DA, Rubin WW, Katz LC (1995) Neuronal domains in developing neocortex: mechanisms of coactivation. Neuron 14:7-17.

Zilles K (1990) Anatomy of the neocortex: cytoarchitecture and myeloarchitecure. In: The cerebral cortex of the rat (Kolb B, Tees RC, eds), pp 77-112. Cambridge, MA: MIT.

Zilles K, Wree A, Schleicher A, Divac I (1984) The monocular and binocular subfields of the rat's primary visual cortex: a quantitative morphological approach. J Comp Neurol 226:391-402. 